\title{
Secondary Hemophagocytosis in Propionic Acidemia
}

\author{
Cigdem Seher Kasapkara ${ }^{1, *}$; Murat Kangin ${ }^{2}$; Banu Oflaz Ozmen ${ }^{3}$; Mehmet Nuri Ozbek ${ }^{4}$; \\ Remezan Demir ${ }^{2}$; Mustafa Karatas ${ }^{2}$; Leyla Tumer ${ }^{5}$; Fatih Suhey Ezgu ${ }^{5}$; Alev Hasanoglu ${ }^{5}$ \\ ${ }^{1}$ Department of Pediatric Metabolism and Nutrition, Diyarbakir Children's Hospital, Diyarbakir, Turkey \\ ${ }^{2}$ Pediatric Intensive Care Unit, Diyarbakir Children's Hospital, Diyarbakir, Turkey \\ ${ }^{3}$ Department of Pediatric Hematology and Oncology, Diyarbakir Children's Hospital, Diyarbakir, Turkey \\ 4 "Department of Pediatric Endocrinology, Diyarbakir Children's Hospital, Diyarbakir, Turkey \\ 5 Department of Pediatric Metabolism and Nutrition, Gazi University Hospital, Ankara, Turkey \\ *Correspanding author:Cigdem Seher Kasapkara, Department of Pediatric Metabolism and Nutrition, Diyarbakir Children’s Hospital, Diyarbakir, Turkey. E-mail: cskasapkara@gmail.com
}

Received: February 1, 2014; Accepted: November 11, 2014

Keywords: Propionic Acidemia; Secondary Hemophagocytosis

\section{Dear Editor,}

Propionic acidemia is one of the intoxication type organic acidemias, which often present in the neonatal period with lethargy, feeding difficulties, hypotonia, vomiting and coma if not identified and treated appropriately. Patients with propionic acidemia can decompensate during periods of increased metabolic demand $(1,2)$. Hemophagocytic lymphohistiocytosis (HLH) is a life threatening disorder that can rapidly deteriorate and lead to multiple organ failure and death. It can be classified as primary (familial) or secondary (acquired) $(3,4)$. Secondary HLH is associated with infections especially viral, malignant disorders, inborn errors of metabolism such as multiple sulphatase deficiency, lysinuric protein intolerance, biotinidase deficiency, Gaucher disease and galactosialidosis (5-8) In this report, we present a case of a 3 year old boy with propionic acidemia who experienced secondary HLH during his metabolic attack and was successfully treated with intravenous gammaglobulin, broad spectrum antibiotics and dexamethasone therapy.

A 3-year-old boy who had been followed up with the diagnosis of propionic acidemia from the neonatal period presented with respiratory distress, somnolance, fever and diarrhea to pediatric metabolic unit. His parents were first degree cousins. Carboxylase activities in cultured fibroblasts confirmed the diagnosis of isolated propionyl COA carboxylase deficiency. He had been admitted to hospital several times due to metabolic attacks. On his last admission, body temprature was $39^{\circ} \mathrm{C}$. He was tachypneic and tachycardic and capillary refilling time was longer than normal. Skin turgor and tonus were decreased. He was dehydrated. He was not oriented and did not cooperate but was able to localize the painful stimuli. During the follow up in intensive care unit, his consciousness deteriorated progressively, and he was intubated. Serum ammonia level was elevated (280, normal range $31-123 \mu \mathrm{g} / \mathrm{dL}$ ) and hyper-ammonemia responded dramatically to a single dose of oral carglumic acid. Over the following 6 hours, the plasma ammonia level dropped to $81 \mu \mathrm{g} / \mathrm{dl}$ and remained normal thereafter. Serum uric acid level was $9.4 \mathrm{mg} / \mathrm{dL}$. Complete blood count revealed hemoglobin $12.7 \mathrm{~g} / \mathrm{dL}$, leucocyte count $3.1 \times 109 / \mathrm{L}$ and platelets $96 \times 10^{9} / \mathrm{L}$. Blood gas analysis showed $\mathrm{pH}: 7.52, \mathrm{pCO}_{2} 10.8$ and $\mathrm{HCO}_{3} 8.7 \mathrm{mmol} / \mathrm{L}$. Plasma lactate was $6,77 \mathrm{mmol} / \mathrm{L}$. Urine was positive for ketones. He was put on broad spectrum antibiotic treatment after several sets of cultures were taken. On the third day of admission, pancytopenia was prominent with hemoglobin $8.2 \mathrm{~g} / \mathrm{dL}$, leucocyte $2.1 \times 10^{9} / \mathrm{L}$, and platelet count $4 \times 10^{9} / \mathrm{L}$. The peripheral smear showed leukopenia, normocytic normochromic anemia, and thrombocytopenia. Serum ferritin level was $1753 \mathrm{ng} / \mathrm{mL}$. Although he was not on parenteral nutrition, serum triglyceride level was $>1420 \mathrm{mg} / \mathrm{dL}$. Plasma fibrinogen level was 87 $\mathrm{mg} / \mathrm{dL}$ (normal range 160 - $400 \mathrm{mg} / \mathrm{dL}$ ). Lactate dehydrogenase level was 1376 IU/L. With the diagnosis of secondary HLH, bone marrow aspiration was performed. On light microscopic examination of bone marrow aspirate, increased histiocytes, lipid laden macrophages, and prominent hemophagocytosis were observed. Viral testing was negative. Based on diagnostic criteria, our patient fulfilled 5 of the 8 criteria and was diagnosed

Copyright (C) 2015, Growth \& Development Research Center. This is an open-access article distributed under the terms of the Creative Commons Attribution-NonCommercial 4.0 International License (http://creativecommons.org/licenses/by-nc/4.0/) which permits copy and redistribute the material just in noncommercial usages, provided the original work is properly cited. 
as HLH. Intravenous gamma globulin was given immediately and dexamethasone added to treatment as ordered in the treatment protocol for Hemophagocytic Lymphohistiocytosis (HLH-2004) (Figures 1-3).

He became better in terms of clinical picture and laboratory findings. Fever decreased strikingly. The blood count normalized day by day. We tapered the steroid dose according to HLH 2004 protocol. Two months after the beginning of HLH 2004 protocol, dexamethasone dosage was decreased. Now he is on regular outpatient clinic visits for propionic acidemia and had no relapse during follow up.

Hemophagocytic lymphohistiocytosis is a potentially fatal hyperinflammatory condition caused by a highly stimulated but ineffective immune response. HLH can be classified according to the underlying etiology into either primary or secondary. HLH may also occur as a secondary disorder in association with severe infections, malignancies, rheumatologic disorders and some metabolic diseases (1). The mechanism is not clear how the metabolites trigger HLH in inborn errors of metabolism. The HLH-2004 diagnostic criteria suggests that to make a diagnosis of HLH, five of the following criteria are required: 1) fever for 7 days, 2) Splenomegaly, 3) unexplained progressive cytopenia of two or more of three lineages: ANC $<1 \times 10^{3} / \mu \mathrm{L}$, hemoglobin $<9$ $\mathrm{g} / \mathrm{dL}$, platelet count $\left.<100 \times 10^{3} / \mu \mathrm{L}, 4\right)$ hypertriglyceridemia $>265 \mathrm{mg} / \mathrm{dL}$ or hypofibrinogen-emia, 5) hyperferritinemia $>500 \mu \mathrm{g} / \mathrm{L}, 6$ ) increased soluble CD25 > 2400 $\mathrm{U} / \mathrm{mL}, 7)$ reduction of natural killer cell activity and 8 ) pathology showing hemophagocytosis (2). Our patient met five of the eight criteria: fever, cytopenia, hypertriglyceridemia, hypofibrinogenemia, elevated ferritin, and pathology showing hemphagocytosis. No infectious agent was demonstrated from multiple cultures and by serological evaluations. Our patient did respond to dexamathasone and intravenous gammaglobulin therapy. Removal of cytokines with plasma exchange can help to maintain patients until other therapies have a chance to work. Plasma exchange could not be done effectively in our center. However we recommend initiation of the treatment with steroid and immune globulin and if the HLH cannot be taken under control, other drugs such as etoposide and cyclosporin A should be added to the therapeutic regimen. Also in resistant secondary HLH cases, plasma exchange may be considered in terms of removing cytokines and toxins from circulation if available $(3,4)$. In conclusion this experience suggests that steroid and immune globulin could be considered as a first line therapy in patients with secondary HLH associated by metabolic diseases. Of course, awareness of the clinical symptoms and diagnostic criteria for hemophagocytic syndrome is crucial to start timely lifesaving therapy. The efficacy of therapeutic measures and prognosis depends on degree of hypercytokinemia-associated organ failure at disease onset and underlying disorders.

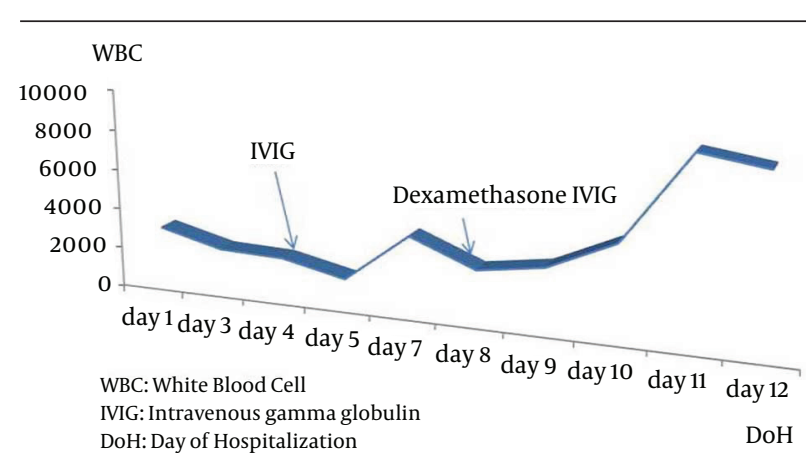

Figure 1. Shows the White Blood Cell Count Levels Variation With the Treatment Protocol

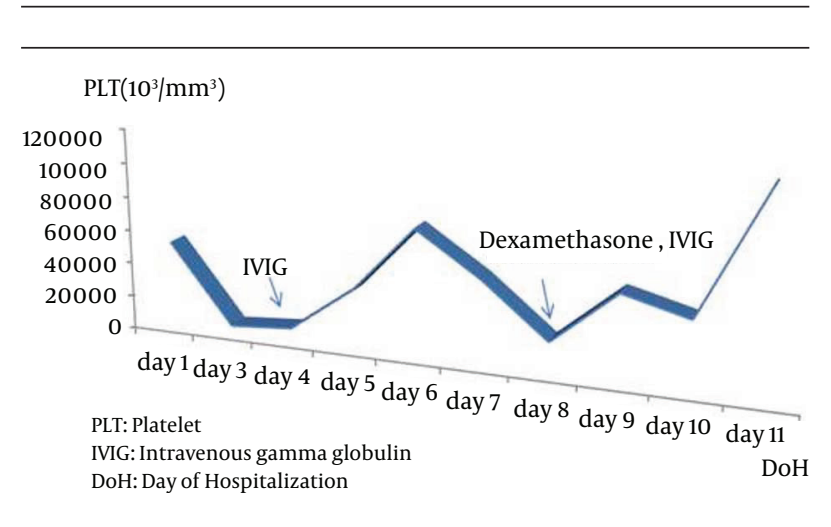

Figure 2. Shows the Platelet Levels Variation With the Treatment Protocol

$\mathrm{Hb}(\mathrm{gr} / \mathrm{dl})$

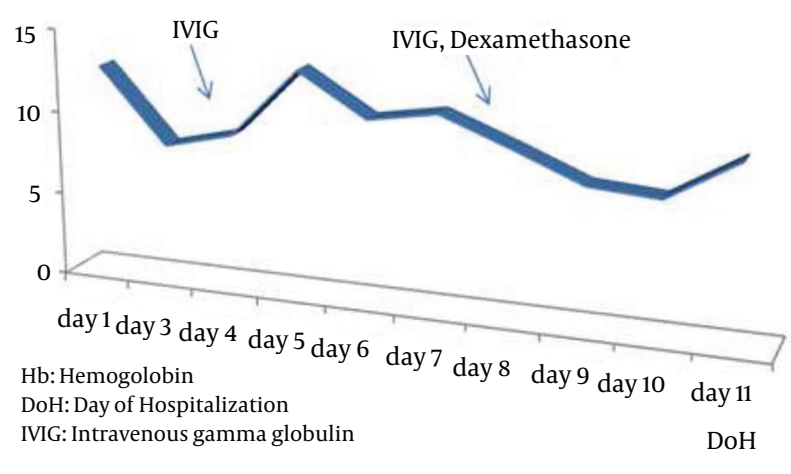

Figure 3. Shows the Hemoglobin Levels Variation With the Treatment Protocol

\section{References}

1. Gokce M, Unal O, Hismi B, Gumruk F, Coskun T, Balta G, et al Secondary hemophagocytosis in 3 patients with organic acidemia involving propionate metabolism. Pediatr Hematol Oncol. 2012;29(1):92-8.

2. Janka GE. Hemophagocytic syndromes. Blood Rev. 2007; 21(5):245-53.

3. Imashuku S. Differential diagnosis of hemophagocytic syn- 


\section{Kasapkara CS et al.}

drome: underlying disorders and selection of the most effective treatment. Int J Hematol. 1997;66(2):135-51.

4. Olcay L, Gumruk F, Boduroglu K, Coskun T, Tuncbilek E. Anaemia and thrombocytopenia due to haemophagocytosis in a 7-month-old boy with galactosialidosis. J Inherit Metab Dis.1998; 21(6):679-80.

5. Janka GE. Familial and acquired hemophagocytic lymphohistiocytosis. Eur J Pediatr. 2007;166(2):95-109.

6. Gursel T, Kocak U, Tumer L, Hasanoglu A. Bone marrow hemo- phagocytosis and immunological abnormalities in a patient with lysinuric protein intolerance. Acta Haematol.1997;98(3):160-2.

7. Mun JI, Shin SJ, Yu BH, Koo JH, Kim DH, Lee KM, et al. A case of hemophagocytic syndrome in a patient with fulminant ulcerative colitis superinfected by cytomegalovirus. Korean J Intern Med. 2013;28(3):352-5.

8. Atteritano M, David A, Bagnato G, Beninati C, Frisina A, Iaria C, et al. Haemophagocytic syndrome in rheumatic patients. A systematic review. Eur Rev Med Pharmacol Sci. 2012;16(10):1414-24. 